\title{
Effect of Lavender Oil Inhalation on Injection Pain Intensity Among Children Undergoing Vaccination
}

\author{
Hanem Abdullha Mohamed Asmaa Mahfouz Hassan \\ Lecturer of Pediatric Nursing, Faculty of Nursing, Cairo University, Cairo, Egypt
}

\begin{abstract}
Background: Pain control and management are the most critical aspects of basic needs, human rights, and nursing care in children. Aim: to evaluate the effect of lavender oil inhalation on injection pain intensity among children undergoing vaccination Design: A quasi experimental research design was utilized to fit the aim of the study. Setting: the study was conducted in selected governmental, ministry of health and population pediatric primary health centers (health offices). Sample: A purposive sample of 100 child, who attended primary health care centers to receive vaccination injections were enrolled either in control (50) or intervention (50) group randomly. Data collection tools: 1) Structured interview questionnaire, related to the personal characteristics of vaccinated children and nurses who give the vaccine; 2) The Modified Behavioral Pain Scale (MBPS) developed by Taddio et al. (1995). 3) cry duration measured in seconds. Results: There was a highly significant difference between the total pain scores and cry duration of control and intervention group immediately and five minutes after injection with $p . \leq 0.05$. There was a highly significant positive correlation between total scores of MBPS immediately and five minutes after injection with cry duration in control group. While there was a highly significant correlation between total scores of MBPS five minutes after injection and cry duration in intervention group $(\mathrm{P} \leq 0.001)$. Conclusion: children who were in the intervention group and received lavender oil inhalation after the injection showed lower pain scores using the MBPS scale and shorter cry duration after vaccination injection than those who were in the control group. Recommendation: pediatric nurses need to conduct more strict experimental randomized trials on larger representative samples to evaluate effect of lavender oil inhalation on injection pain reduction among children.
\end{abstract}

Keywords: pain, vaccination, children, pediatric nurses, lavender oil inhalation

DOI: $10.7176 / \mathrm{JHMN} / 73-08$

Publication date: April $30^{\text {th }} 2020$

\section{Introduction and Literature Review}

Vaccinations are the most effective way of preventing infectious diseases, even though vaccination is an invasive procedure that involves infants worldwide (MacLennan \&Saul 2014).Vaccination is one of the most common causes of pain associated with medical procedures in healthy infants and children (Halpert et al. 2015, and Ciftci et al. 2016). Pain is defined by Cohen et al. (2018) as an unpleasant sensory and emotional experience associated with actual or potential tissue damage or described in terms of such damage.

Exposure to unalleviated pain early in life has immediate and long-lasting implications for sensory perception, stress tolerance, and emotional well being that are characterized by a hypo-/hyper-sensitivity in response to acute versus chronic and/or severe stimuli. Changes in brain development and cognition, as well as immune function, have also been identified. The mechanisms by which such long-term changes occur are not completely clear, but accumulating evidence indicates that changes in endogenous opioids, as well as the stress related hormones or peptides (glucocorticoids, CRF) and their receptors, contribute to the observed changes. Early life greatly raises the risk for the development of anxiety, depression and potentially PTSD and the use of specific and effective analgesic/anesthetic regimens for human infants is crucial (Victoria \& Murphy 2016).

Role of the pediatric nurse is crucial in the process of pediatric vaccination, this role include reduce parental hesitance to vaccination process, assess children before the vaccination for presence of fever, cough, running nose. The nursing assessment include the rote of vaccination if oral or injection. Pain is one of the problems that encountered by children and their parents. Pediatric nurses are of great help for children and their parents in overcoming the pain. It is very critical multilayer complex role to play every day for children as well as their parents (Stevens \& Marvicsin 2016).

Pain control is one of the key tasks of pediatric nursing. Management and control of pain in infants is one of the most important critical roles and duties of nurses, and the search and use of all possible methods for this purpose should be considered (Razaghi et al. 2015). Pain control and management are the most critical aspects of basic needs, human rights, and nursing care in children. Pain is managed by pharmacological and non-pharmacological methods including complementary therapy (Bikmoradi et al. 2016). Some of the medications used to alleviate pain have limitations and side effects such as lidocaine spray, which can cause allergic reactions, systemic absorption, and even cardiac dysrhythmia (Giordano et al.2015).

Non-pharmacological approaches, on the other hand, are low-risk, feasible, and accessible and present a costbenefit to the nursing sector as well. Complementary therapies include many methods such as meditation, body 
relaxation, music therapy, and aromatherapy (Bikmoradi et al. 2014). Aromatherapy refers to the medical or therapeutic use of essential oils absorbed through the skin or olfactory system. Some studies indicate that olfactory stimulation related to aromatherapy may result in immediate reduction in pain, as well as changing physiological parameters such as pulse, blood pressure, skin temperature, and brain activity (Lakhan 2016).

Aromatherapy is known as a medical procedure supplementing positive effects which have been tested in many studies. As a result of rapid growth of aromatherapy in the world and the tremendous interest in this therapy, as well as the study of aromatherapy in different diseases, it has been suggested that nurses should use this therapy at their workplaces and homes. According to the studies, the most widely used application of aromatherapy is through inhalation, as it is simple, fast and efficient. Aromatherapy with lavender helps to manage pain in various patients by inhalation. However, more studies are needed to support this assertion (Abbaszadeh et al. 2017).

The use of aromatherapy to relieve pain has grown substantially in recent years compared with other alternative therapies. Aromatherapy is one of the complementary or alternative treatment approaches that is believed to be effective in alleviating pain, reducing anxiety, insomnia, depression, fatigue, asthma, antiinflammatory and anti-microbial. In reality, the aromatherapy is both science and art (Meghani et al. 2017).

Herbal oil is useful as an alternative remedy for pain and inflammation, as use of herbal preparation is free of side effects (Chauhan 2016). These types of oils are 100\% herbal (which makes them quite affordable), have no significant side effects, are non-invasive and have no medical interventions. They're easy and inexpensive, and they're better accepted by patients and are widely used in nursing cares. Pharmacological studies evidence that essential oils have a therapeutic potential for the treatment of many diseases and promising use as compounds with analgesic-like action (DaSilveira et al. 2017).

Aromatherapy is used by massage and inhalation therapies and baths with herbal essence oils and mineral substances (Popovic, Matic, Bojovic, Stefanovic, \& Vidakovic 2016). One of the useful methods of utilizing aromatherapy products is to formulate them in the form of respiratory, fumigation and spraying of products which spread the aromatic material's particles gained through oil refining in the air. These particles are then inhaled and absorbed by the body (Ueki et al. 2015).

Lavender (Lavandula Angustifolia) is one of the essential oils used in aromatherapy; two methods of administering lavender oil are recommended topically and by inhalation. Inhalational aromatherapy is a procedure in which essential oils are used for inhalation, which can alleviate pain, mental stress, and depression, and improve vital signs (Seifi et al. 2014). Lavender is an aromatic herb that belongs to the Lamiaceae family and exhibits antibacterial, anti-fungal, anti-bloating, relaxing muscle and analgesic effects (Ali et al. 2015). The use of aromatherapy, particularly lavender inhalation essence can reduce consumption of chemical medicines among patients (Najafi et al. 2016).

Lavender oil has been known to have sedative properties for centuries, and it is one of the most effective aromatherapy oils. It stimulates the parasympathetic system and reduces blood pressure and anxiety levels consequently (Elbay et al. 2016). Dose-dependent sedative-like drug effects were also demonstrated in several studies, and supplements have been started to be used in clinical practice recently. Adverse effects such as prolonged sedation with the use of GABA receptor agonist sedative drugs can be prevented by preferring lavender oil aromatherapy instead, in proper case selections (Arslan et al. 2020). Lavender oil inhalation has proven to be of use in reducing anxiety levels of patients undergoing coronary artery bypass, (Seifi et al. 2014) and on vital signs(Karan 2019), and in reducing pain due to intravenous catheter insertion in preschool children (Bikmoradi et al. 2017) and in dental anxiety and pain reduction in children (Arslan et al. 2020)

\subsection{Study Significance:}

Numerous studies in adults have examined the effect of lavender oil aromatherapy for pain relief has been studied, and in study done by Karaman et al. (2016) assessed the efficacy of lavender aromatherapy on peripheral venous cannulation pain and anxiety, the finding of their results showed that Lavender aromatherapy had beneficial effects on the peripheral venous cannulation (PVC) pain, anxiety, and satisfaction level of patients undergoing surgery. Also study performed by Ziyaeifard et al. (2017) found that smelling the scent of lavender significantly reduced anxiety and pain in patients, before and after coronary angiography.

Another research conducted by Khalil et al. (2018) found that inhalation of lavender oil can be used in conjunction with analgesics /opioids to relieve pain in patients after open heart surgery to minimize the intake of narcotics and nonnarcotic drugs and their deleterious effects. Whereas another research by Maedeh, et al., (2019) on the comparison of the impact of entonox gas and lavender aromatherapy on the severity of labor pain has shown that entonox gas and lavender aromatherapy can both reduce the severity of labor pain. Yet the role of Entonux gas is greater in reducing labor pain than in lavender.

However, there is a small number of studies engaging aromatherapy on pain in infants and toddlers as a non - pharmacological and noninvasive method that can be easily utilized. In addition, there is recommendation for further research studies to be conducted on the pain relief capacity of natural aromatic agents such as the lavender oil in infancy (Vaziri et al. 2019). Therefore on the basis of the findings of this study, as well as the researchers' 
interest and willingness to use lavender as a complementary method, it could be applied as a feasible, safe, and inexpensive method to reduce pain severity of vaccine injection site. So, the aim of the current study was to evaluate the effect of Lavender oil inhalation on injection site pain intensity among children undergoing vaccination

\subsection{Aim of the study:}

The aim of the current study was to evaluate the effect of Lavender oil inhalation on injection pain intensity among children undergoing vaccination

\subsection{Research hypotheses:}

1- Children who inhale lavender oil after vaccination will have lower total mean score of pain based on modified Behavioral Pain Scale than those in the control group.

2- Children who inhale lavender oil after vaccination will show shorter cry duration than those in the control group.

\section{Methods}

\subsection{Research Design:}

A two groups, quasi-experimental research design was utilized to fit the aim of the study. A quasi-experimental design is one type of effective research designs that is very helpful to the true experimental design except for either complete laboratory control on the extraneous variables that might affect the results nor randomization which affects the generalizability of the results (Polit \& Beck 2017).

\subsection{Setting:}

The study was conducted in selected ministry of health and population, governmental pediatric primary health centers (health offices) in Helwan suburb, Cairo, Egypt.

\subsection{Sample:}

A purposive sample of 100 children aged 40 days to 1.5 years old, who attended the vaccination clinics in some selected governmental pediatric primary health care centers (health offices) and subjected to subcutaneous vaccination injection procedure participated in the current study.

2.4. Subject assignment: Children were assigned randomly into two groups: the first (50 children) were considered as control group received the routine care, and the second (50 children) were considered as study group who were subjected to the lavender oil inhalation.

\subsection{Inclusion criteria}

The following characteristics are used to enroll children in the study:

- Well children only (not ill or have any signs of illness like fever, running nose, diarrhea, etc.)

- Children who has no systemic disease (diabetes, vascular disease, congenital anomaly, .. etc).

- Children who has no history of hospitalization for any reason (as hospitalization has been long time known as experience that is linked with painful experiences and that may affect the children in results).

- $\quad$ Free from bleeding disorders or hematologic disorders (as bleeding disorders may result in bleeding after injection and that will complicate the situation and interfere with the measurement of the desired outcome).

\subsection{Exclusion Criteria}

- Children who received vaccination children with a needle size more than $2.5 \mathrm{~cm}$ syringe.

- Children who had complications related to vaccination injection like bleeding, trauma, contusion, hematoma, ...etc.

- Children who it was difficult for the nurse to give them the vaccination injection related to presence of any skin or subcutaneous tissue health problem (old hematoma, skin infection, ..etc)

\subsection{Ethical Considerations}

An oral consent was obtained from the mothers of the children after clear explanation of the purpose and nature of the study in order to obtain their acceptance as well as their cooperation. The researcher assured mothers that all data gathered during the study are confidential and that they can withdraw from study without any effect on the care provided to their children. For research ethical consideration and based on the basic ethical principles of beneficence, data were collected firstly from children in the control group.

2.8. Data collection tools: The required data was collected through the following two tools:

1- Structured interview questionnaire: It was developed by the researchers; it includes 13 questions to assess 
personal data of children and nurses who provide the vaccination such as (age, gender, duration of cry in seconds, etc).

2- Modified Behavioral Pain Scale (MBPS) developed by Taddio et al. (1995) and contained three main categories: (I) facial expression, (II) cry and (III) movement.

3- Cry duration in seconds

\subsection{Scoring system}

The modified Behavioral Pain scale (BPS) is used to determine the severity of pain in children during and after vaccination procedure based on children's behavioral responses. This scale is three main items, and 15 sub items as the following: face (4 sub items); cry ( 5 sub items) and movement ( 6 sub items). The total score ranged from $0-10$, with (0) indicate no pain and (10) severe worst pain.

\subsection{Validity and Reliability}

Data collection tool (the structured interview sheet) was submitted to five experts from pediatric nursing field to test the content validity. Modifications of the tools were done according to the experts' judgment on clarity of sentences, appropriateness of content and sequence of items. The experts' agreed on the content but recommended minor language changes that would make the information clearer and more precise. Modified Behavioral Pain Scale (MBPS) according to Taddio et al. (1995) had been tested and found to be valid, reliable and sensitive tool to assess procedure pain (Crellin et al. 2017 and Crellin et al. 2018).

\subsection{Data Collection Procedures}

Before conducting the study an official permission was obtained from the directors of the governmental primary health care centers, after explaining the nature of the study. The researchers meet the mothers in the nurses room, introduced self to the mothers. Acceptance was obtained from mothers of children in the study. Clear and simple explanations about the aim and nature of the study were discussed by the researchers with mothers, then filled structured interview questionnaire.

For the study group: immediately after the vaccination injection, the researchers assessed child pain score (base line) using the MBPS. Five drops of the lavender essential oil were spilled on a cotton ball and held near the nose of the child to inhale while the child was left for 5 minutes in his mother's lap. Then the child pain score was assessed again using the MBPS as well as the crying duration.

For the control group: immediately after vaccination injection, the researcher assessed the child pain using the MBPS (baseline). The child was left without any manipulation in his mother's lap, then pain was assessed again by MBPS, as well as the crying duration.

The children in control or intervention group were observed for MBPS pain assessment in the vaccination room. The time needed for each child ranged from 15-20 minutes including the MBPS assessment before and after vaccination injection, vaccination, and inhaling the lavender oil (if an intervention group). Data collection was conducted over five months extending from October 2019 till February 2020.

\subsection{Pilot study}

Pilot study was carried out on $10 \%$ of the sample children to assess the feasibility, objectivity, applicability, clarity, adequacy, and content validity of the study tools and time required to fulfill its aim and to determine possible problems in the methodological approach or instrument. The results of the pilot study were used to test the proposed statistical and data analysis methods. The tools were completed without difficulty, adding support to the validity of the instrument. Children who participated in the pilot study were included to the total sample.

\subsection{Statistical analysis}

The collected data tabulated, and summarized. A statistical package for social studies (SPSS) version 20 was used for statistical analysis of data. Data was computerized and analyzed using appropriate descriptive and inferential statistical tests. Qualitative data were expressed as frequency and percentage. Mean and SD were used to evaluate the quantitative variables (age) and absolute and relative frequency was used to evaluate the gender. Independent T-test was used to assess changes in mean pain between the two groups, and r. test was used to measure correlational relationship between selected variable. In this study, a significant level of $\mathrm{P}<0.05$ was considered. 


\section{Results}

Table (1) Children' Age, Sex and Injection Site in Control and Intervention Group in Percentage Distribution ( $\mathbf{n}=100)$.

\begin{tabular}{|c|c|c|c|c|}
\hline \multirow[t]{2}{*}{ Characteristics } & \multicolumn{2}{|c|}{ Control Group $(n=50)$} & \multicolumn{2}{|c|}{ Intervention Group $(n=50)$} \\
\hline & No & $\%$ & No & $\%$ \\
\hline \\
\hline - Male & 28 & 56 & 21 & 42 \\
\hline - Female & 22 & 44 & 29 & 58 \\
\hline$\chi^{2}$ & \multicolumn{4}{|c|}{0.163} \\
\hline P. value & \multicolumn{4}{|c|}{0.686} \\
\hline \multirow{4}{*}{$\begin{array}{l}\text { Age (months): } \\
-1 \leq 6 \\
-7 \leq 12 \\
=13 \leq 18\end{array}$} & & & & \\
\hline & 25 & 50 & 39 & 78 \\
\hline & 17 & 34 & 8 & 16 \\
\hline & 8 & 16 & 3 & 6 \\
\hline \multirow{3}{*}{$\begin{array}{l}\text { Mean+ SD } \\
\text { t. test } \\
\text { P. value }\end{array}$} & \multicolumn{2}{|c|}{$8.08+5.41$ years } & \multicolumn{2}{|c|}{$5.44+4.75$ years } \\
\hline & \multirow{2}{*}{\multicolumn{4}{|c|}{$\begin{array}{c}8.088 \\
0.000 *\end{array}$}} \\
\hline & & & & \\
\hline \multirow{3}{*}{$\begin{array}{l}\text { Injection site: } \\
\text { - Arm (BCG) } \\
\text { - Leg (DPT) }\end{array}$} & & & & \\
\hline & 8 & 16 & 18 & 36 \\
\hline & 42 & 84 & 32 & 64 \\
\hline$\chi^{2}$ & \multicolumn{4}{|c|}{0.002} \\
\hline P. Value & \multicolumn{4}{|c|}{0.969} \\
\hline
\end{tabular}

*Highly significant at $\mathrm{P} \leq 0.01$

Table (1) revealed that, more than half of children (56\%) in control group were male, while more than half of children $(58 \%)$ in intervention group were female. Concerning children age, the highest percentage of children were between $1 \leq 6$ months in control and intervention group ( $50 \%$ and $78 \%$ respectively) while the minority of children their age were between $13 \leq 18$ months in control and in intervention group (16\% and $6 \%$ respectively). The total mean ages of children in control group were 8.08 \pm 5.41 months while in intervention group the mean age of children were $5.44+4.75$ months. As regard to injection site, table (1) illustrated that the highest percentage of injection site was the leg in control and intervention group (84\% and $64 \%$ respectively). In relation to sex of child and site of injection both control and intervention group were homogenous as $(\chi 2=0.163 \& 0.002$ respectively) with $P$. value $\geq 0.05$. While there was a highly significant difference between the two groups in relation to age of children $(\mathrm{t} .=8.088, \mathrm{p} .=0.000)$

Table (2) Percentage Distribution of Nurse's Age, Sex, Years of Experience and Education ( $n=7)$.

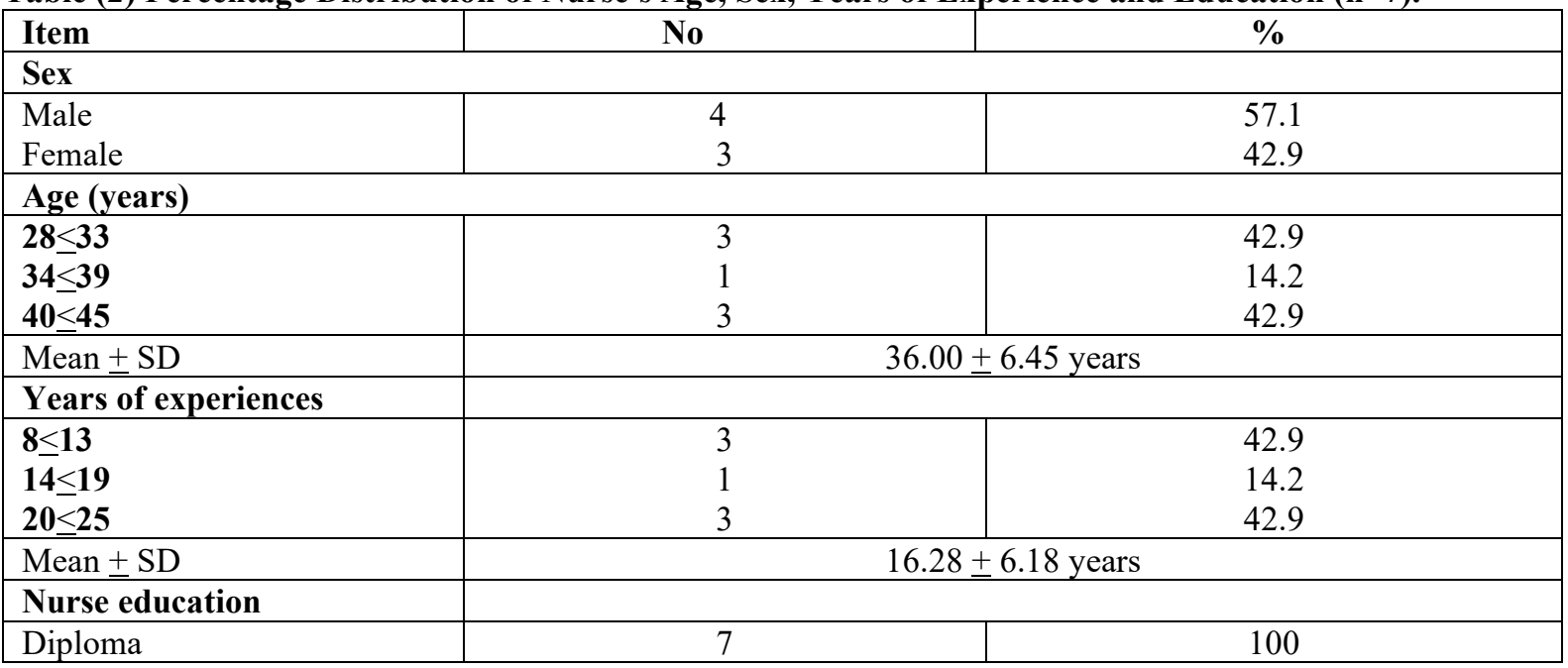

It was evident from table (2) that, more than half of nurses (57.1\%) were male, and above two fifths of nurses $(42.9 \%)$ aged between $(28 \leq 33$ years old and $40 \leq 45$ years old $)$ with total mean age $36.00 \pm 6.45$ yrs. Concerning nurses' experience, table (2) showed that (42.9\%) of nurses had years of experiences of $(8 \leq 13$ years and $20 \leq 25$ years $)$ with total mean of $(16.28 \pm 6.18$ years $)$, and all of them had a $(100 \%)$ a diploma degree. 
Table (3) Percentage Distribution of Facial Component of MBPS Immediately and Five Minutes After Injection in Control and Intervention Group $(\mathbf{n}=100)$.

\begin{tabular}{|c|c|c|c|c|c|c|c|c|}
\hline (BPS) & \multicolumn{4}{|c|}{ Control group $(n=50)$} & \multicolumn{4}{|c|}{ Intervention group $(\mathrm{n}=\mathbf{5 0})$} \\
\hline \multirow[t]{2}{*}{ Facial } & \multicolumn{2}{|c|}{$\begin{array}{l}\text { Immediately } \\
\text { after injection }\end{array}$} & \multicolumn{2}{|c|}{$\begin{array}{l}\text { Five minutes } \\
\text { After injection }\end{array}$} & \multicolumn{2}{|c|}{$\begin{array}{l}\text { Immediately } \\
\text { after injection }\end{array}$} & \multicolumn{2}{|c|}{$\begin{array}{l}\text { Five Minutes } \\
\text { After } \\
\text { injection (and } \\
\text { lavender } \\
\text { inhalation) }\end{array}$} \\
\hline & No & $\%$ & No & $\%$ & No & $\%$ & No & $\%$ \\
\hline $\begin{array}{l}\text { Definite positive expression } \\
\text { (smiling) }\end{array}$ & 0 & 0 & 0 & 0 & 0 & 0 & 21 & 42 \\
\hline Neutral expression & 0 & 0 & 0 & 0 & 0 & 0 & 26 & 52 \\
\hline $\begin{array}{l}\text { Slightly negative expression } \\
\text { (grimace) }\end{array}$ & 0 & 0 & 0 & 0 & 0 & 0 & 3 & 6 \\
\hline $\begin{array}{l}\text { Definite negative expression } \\
\text { (furrowed brow eyes closed } \\
\text { tightly) }\end{array}$ & 50 & 100 & 50 & 100 & 50 & 100 & 0 & 0 \\
\hline
\end{tabular}

Table (3) highlighted facial percentage as one component of Modified Behavioral Pain Scale (MBPS), it was clear from table that all children $(100 \%)$ in control group had definite negative expression immediately after injection and five minutes after injection. While in intervention group, all children $(100 \%)$ immediately after injection had facial definite negative expression and five minutes after injection and lavender oil inhalation, the highest percentage of them were facial neutral expression and facial definite positive expression (52\% and $42 \%$ respectively).

Table (4) Percentage Distribution of Cry Component of MBPS Immediately and Five Minutes After Injection in Control and Intervention Groups $(\mathbf{n}=100)$

\begin{tabular}{|c|c|c|c|c|c|c|c|c|}
\hline (BPS) & \multicolumn{4}{|c|}{ Control group $(n=50)$} & \multicolumn{4}{|c|}{ Intervention group $(\mathrm{n}=\mathbf{5 0})$} \\
\hline \multirow[t]{2}{*}{ Cry } & \multicolumn{2}{|c|}{$\begin{array}{l}\text { Immediately } \\
\text { after injection }\end{array}$} & \multicolumn{2}{|c|}{$\begin{array}{l}\text { Five minutes } \\
\text { After injection }\end{array}$} & \multicolumn{2}{|c|}{$\begin{array}{l}\text { Immediately } \\
\text { after injection }\end{array}$} & \multicolumn{2}{|c|}{$\begin{array}{l}\text { Five Minutes } \\
\text { After } \\
\text { injection (and } \\
\text { lavender } \\
\text { inhalation) }\end{array}$} \\
\hline & No & $\%$ & No & $\%$ & No & $\%$ & No & $\%$ \\
\hline Laughing or giggling & 0 & 0 & 0 & 0 & 0 & 0 & 22 & 44 \\
\hline Not crying & 0 & 0 & 0 & 0 & 0 & 0 & 19 & 38 \\
\hline $\begin{array}{l}\text { Moaning quiet vocalizing gentle or } \\
\text { whimpering cry }\end{array}$ & 0 & 0 & 1 & 2 & 0 & 0 & 8 & 16 \\
\hline Full lunged cry or sobbing & 9 & 18 & 13 & 26 & 1 & 2 & 1 & 2 \\
\hline $\begin{array}{r}\text { Full lunged cry more than baseline } \\
\text { cry (scored only if child crying at } \\
\text { baseline) }\end{array}$ & 41 & 82 & 36 & 72 & 49 & 98 & 0 & 0 \\
\hline
\end{tabular}

Table (4) revealed cry percentage as one component of Modified Behavioral Pain Scale (MBPS), the table showed that most of children in control group had full lunged cry more than baseline cry immediately after the injection and five minutes after it ( $82 \%$ and $72 \%$ respectively). While in intervention group, the majority of children (98\%) immediately after the injection had full lunged cry more than baseline cry and five minutes post injection and inhalation of lavender oil, the highest percentage of children were laughing or giggling and not crying (44\% and $38 \%$ respectively). 
Table (5) Percentage Distribution of Movement Component of MBPS Immediately and Five Minutes After Injection in the Control and Intervention Groups $(n=100)$.

\begin{tabular}{|c|c|c|c|c|c|c|c|c|}
\hline (BPS) & \multicolumn{4}{|c|}{ Control group $(n=50)$} & \multicolumn{4}{|c|}{ Intervention group $(\mathrm{n}=\mathbf{5 0})$} \\
\hline \multirow[t]{2}{*}{ Movement } & \multicolumn{2}{|c|}{$\begin{array}{c}\text { Immediately } \\
\text { after injection }\end{array}$} & \multicolumn{2}{|c|}{$\begin{array}{c}\text { Five minutes } \\
\text { After injection }\end{array}$} & \multicolumn{2}{|c|}{$\begin{array}{c}\text { Immediately } \\
\text { after injection }\end{array}$} & \multicolumn{2}{|c|}{$\begin{array}{l}\text { Five Minutes } \\
\text { After } \\
\text { injection (and } \\
\text { lavender } \\
\text { inhalation) }\end{array}$} \\
\hline & No & $\%$ & No & $\%$ & No & $\%$ & No & $\%$ \\
\hline $\begin{array}{l}\text { Usual movements and activity or } \\
\text { resting and relaxed }\end{array}$ & 0 & 0 & 0 & 0 & 0 & 0 & 21 & 42 \\
\hline $\begin{array}{l}\text { Partial movement (squirming } \\
\text { arching limb tensing clenching) } \\
\text { attempt to avoid pain by } \\
\text { withdrawing the limb where } \\
\text { puncture is done }\end{array}$ & 1 & 2 & 4 & 8 & 0 & 0 & 29 & 58 \\
\hline $\begin{array}{l}\text { Agitation with } \\
\text { complex/generalized movements } \\
\text { involving the head torso or other } \\
\text { limbs or rigidity }\end{array}$ & 49 & 98 & 46 & 92 & 50 & 100 & 0 & 0 \\
\hline
\end{tabular}

Table (5) pointed to movement percentage as one component of Modified Behavioral Pain Scale (MBPS), it was clear from table that majority of children were agitated with complex/generalized movements or rigid in control group immediately after the injection and after injection (98\% and $92 \%$ respectively). While in intervention group, all children (100\%) immediately after the injection had showed agitation with complex/generalized movements or rigidity and five minutes after the injection and inhalation of lavender oil, the highest percentage of them had partial movement and usual movements and activity or resting and relaxed (58\% and $42 \%$ respectively).

Table (6) Comparison Between Total Mean Scores of MBPS Immediately and Five Minutes After Injection in the Control and Intervention Groups $(n=100)$.

\begin{tabular}{|l|c|c|c|c|}
\hline \multirow{2}{*}{ Item } & \multicolumn{2}{|c|}{ Control group(n=50) } & \multicolumn{2}{c|}{ Intervention group (n=50) } \\
\cline { 2 - 5 } & $\begin{array}{c}\text { Mean +SD } \\
\text { Immediately after } \\
\text { the injection }\end{array}$ & $\begin{array}{c}\text { Mean } \mathbf{E S D} \\
\text { Five minutes } \\
\text { after injection }\end{array}$ & $\begin{array}{c}\text { Mean } \pm \text { SD } \\
\text { Immediately } \\
\text { after the } \\
\text { injection }\end{array}$ & $\begin{array}{c}\text { Mean } \pm \text { SD } \\
\text { Five minutes } \\
\text { after injection } \\
\text { (and lavender } \\
\text { inhalation) }\end{array}$ \\
\hline Total scores of MBPS & $9.80 \pm 0.404$ & $9.62 \pm 0.602$ & $9.98 \pm 0.141$ & $2.56 \pm 2.26$ \\
\hline t-test & 171.500 & 112.926 & 499.000 & 7.977 \\
\hline P-value & $0.000^{*}$ & $0.000^{*}$ & $0.000^{*}$ & $0.000^{*}$ \\
\hline
\end{tabular}

*Highly significant at $\mathrm{P} \leq 0.01$

Regarding total mean scores of Modified Behavioral Pain Scale (MBPS) in control and intervention group, table (6) proved that the total mean pain score of MBPS in control group was more than the lavender intervention group five minutes after injection $(9.62 \pm 0.602$ and $2.56 \pm 2.26$ respectively). Also there was high statistical significance difference between control and intervention group in relation to the total scores of Modified Behavioral Pain Scale (MBPS) (p. $=0.000)$

Table (7) Comparison Between the Total Cry Duration Among the Control and Intervention Groups $(\mathbf{n}=\mathbf{1 0 0})$.

\begin{tabular}{|l|c|c|}
\hline \multirow{2}{*}{ Item } & $\begin{array}{c}\text { Control group } \\
(\mathbf{n = 5 0 )}\end{array}$ & Intervention group (n=50) \\
\cline { 2 - 3 } & Mean + SD & Mean + SD \\
\hline Cry duration (second) & $428.80+239.66$ & $28.00+17.11$ \\
\hline t-test & \multicolumn{2}{|c|}{$0.000^{*}$} \\
\hline P-value & \multicolumn{2}{|c|}{0.570} \\
\hline
\end{tabular}

*Highly significant at $\mathrm{P} \leq 0.01$

Concerning total mean of cry duration (second) in the control and intervention group, table (7) illustrated that the total mean cry duration in the control group was more than intervention group $(428.80+239.66$ and $28.00+17.11$ second respectively). Also there were high statistical significance difference between control and intervention group in relation to the total mean of cry duration $(\mathrm{p} .=0.000)$ 
Table (8) Correlation Between Total MBPS Scores Immediately and Five Minutes After Injection and Child Age, Nurses' Experience, and Cry Duration in Control and Intervention Groups (n=100).

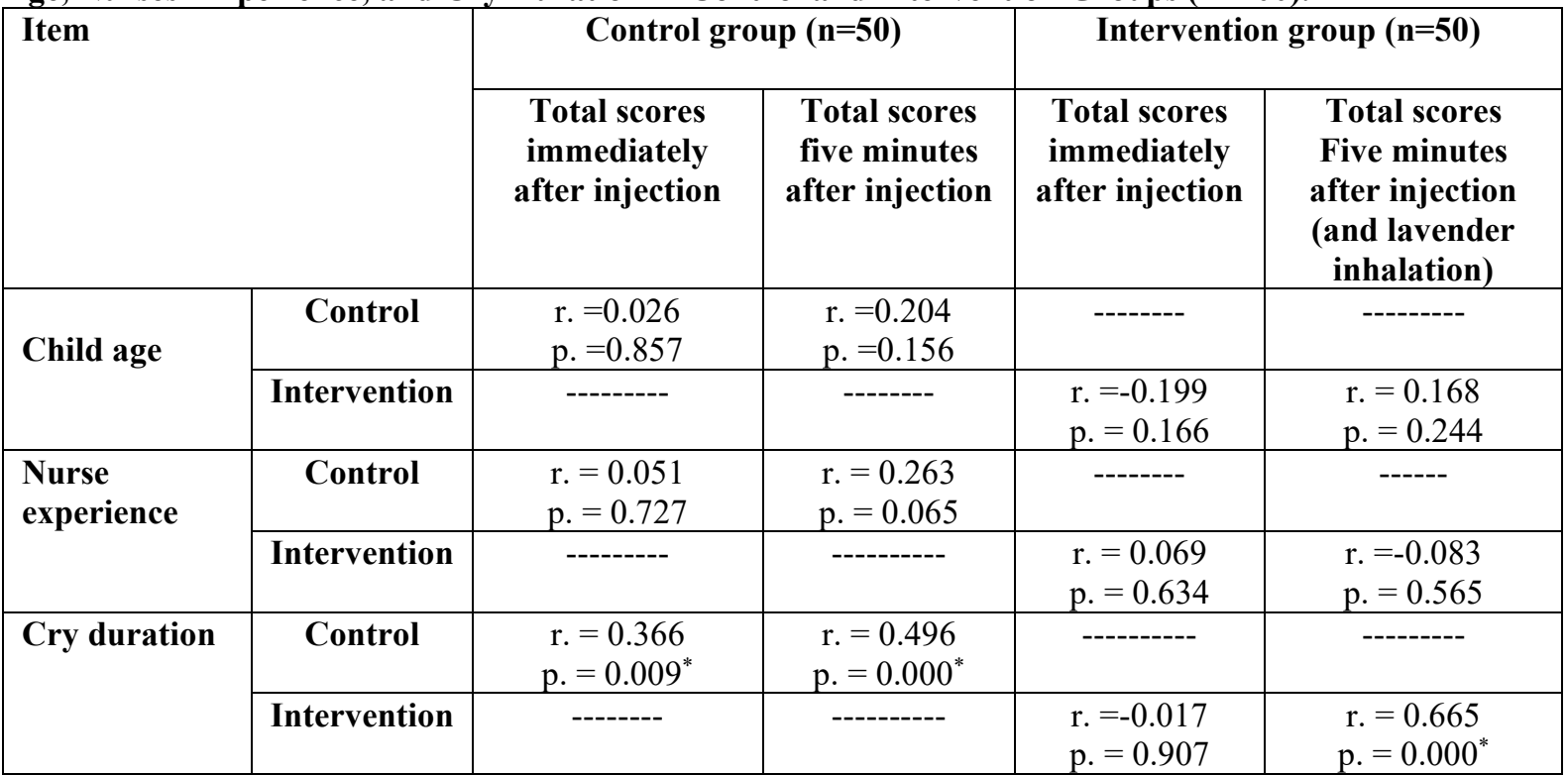

*Correlation is significant at the 0.01 level (2-tailed).

Table (8) revealed that there was a highly significant positive correlations between total scores of MBPS immediately after and five minutes after injection with cry duration in control group $(\mathrm{r} .=0.366, \mathrm{p} .=0.009$ and $\mathrm{r}$. $=0.496, \mathrm{p} .=0.000$ respectively). While there was a highly significant correlation between total scores of MBPS five minutes after injection (after inhalation of lavender oil too) and cry duration in intervention group (r. $=0.665$, p. $=0.000)$.

\section{Discussion}

The results of the current study revealed that, almost half of children in the current study were male and aged below 2 years old. This result is similar of Kenji et al. (2019) who found in their study of demographic and geographical characteristics of pediatric patients presenting to a convenient clinic at a large railway station in a metropolitan area of Tokyo that the majority of the children aged up to three years old and male slightly more than female. The at hand study revealed that the injection site was either the arm or the leg in. This result could be explained and understood with the age of the children in both group. As we see the age of the children was 1-6 months in more than half of them and during this age it is either BCG vaccination as per the Egyptian vaccination schedule or the DPT.

All the nurses in the current study had a diploma degree. From the researcher perspectives, this result could be understood as the ministry of health and population in Egypt is the authorized entity that decide the assignment of nurses to governmental hospitals and health care entities and usually nurses with a bachelor degree (either from the governmental or the private universities) are to be assigned to general hospitals, or university hospitals rather than the primary health care centers.

The current study revealed that after the injection children in the control group had cried for period seven minutes, their face expression was angry and full lunged cry, and body movement showed with agitation. These findings are similar to the results of Gad et al. (2019) who studied the effect of breast feeding on immunization pain among Egyptian infants and found that infants in the control group and sucarose group were crying and showed higher pain scores than those in the breast feeding group.

Five minutes post vaccination injection the total means MBPS scores was higher than immediately after in the control group in this study. This result is with total agreement with the results of Chawda, et al., (2019) who in their study of vaccination related pain using a randomized controlled trial that the mean score of control group children using modified BPS before injection higher than after the injection. In the current study there was a highly significant difference in cry duration and total MBPS after the use of lavender oil inhalation. These findings are in congruent with those of Razaghi et al. (2015), who studied the effect of lavender scent on pain of blood sampling in term neonates, and found that the scent of lavender is effective in reducing the pain of blood sampling in term neonate.

Another study showed agreement with the above mentioned result of the at hand study done by Bikmoradi, et. al., (2017), in which the researchers found that inhalation aromatherapy with lavender essence helped to reduce pain severity of venous catheter insertion in hospitalized preschool children. In the same line analysis conducted by Vaziri et al. (2019), who studied the effect of aromatherapy by lavender oil on infant vaccination pain using a 
double blind randomized controlled trial and found that the duration of neonatal crying as well as the neonatal pain score was lowered significantly in the lavender group. However, the cry duration reduction in the at hand study is contradicting the results of Razaghi et al. (2015) who studied the effect of Lavender scent on pain of blood sampling in term neonates and found that pain scores were lower in the lavender group than the control group.

The current study showed that children who were subjected to lavender oil inhalation had showed after the injection face reaction as neutral or smiling face, shorter crying period, and body movement was more at ease and not showing abnormal movements. These results are explained by the information listed about lavender oil effect listed by Kaviani et al. (2014) who stated that the aromatic essence is inhaled, aromatic impulse enters the brain via the olfactory receptor, resulting in the release of the nervous substances and endorphin hormones, which causes physical and mental changes. Also, Lesage-Meessen et al. (2015) and Algieri, et al. (2016) agreed with the recent results of this study as they earlier found that lavender oil inhalation caused mood-enhancing and sedative properties and reduce muscle spasm.

The current study found that there was a highly significant positive correlations between total scores of MBPS immediately and five minutes after injection with cry duration in control group and intervention study. This result mean that the higher the total pain score the longer the crying time of the child. This result is of similarity with a study that measured the effect of cartoon watching on the pain caused by venipuncture among children by Akgül et al. (2019).

The current study found no correlation between total mean pain scores and child age. This result is contradicted by the findings of Mohamed (2020) in a study of effect of cell phone interactive game on the venipuncture pain among children, the researcher found a negative correlation between the age of children and the attained pain scores using FLACC scale. However, the researchers can explain those results as the age group and setting of the two studies could be the cause of contradiction of results.

Also in the at hand study, there was no correlation between or nurses' years of experience and pain score of children which is contradicting the findings of MacDougall et al. (2018) who studied measures that can reduce vaccination pain among children and found that increase nurses knowledge and experience in relation to methods of pain reduction is of great effect on children pain during vaccination process. The researchers thought that even though the years of experience vary between the nurses in the current study but those nurses expressed to the researcher that they did not receive any educational sessions, instructions or in-service training on nonpharmacological pain management during children vaccination which make the years of experience is only a number that reflects no actual experience nor effect on their skills of pain management of children.

\section{Conclusion}

The current study concluded that children who inhaled lavender oil after vaccination injection had showed lower pain scores using the modified behavioral pain scale and shorter cry duration than children in the control group.

\section{Recommendations}

The at hand study recommended that:

1- Non-pharmacological pain relief as lavender oil inhalation need to be explored and used in primary health care centers to control children pain during immunization process.

2- In-service training programs need to be conducted in primary health care centers in Egypt to raise nurses awareness on pain and its effect on children health and how to manage it.

3- Stricter experimental randomized trials need to be conducted on larger representative samples to evaluate effect of lavender oil inhalation on injection pain reduction among children.

\section{Acknowledgement}

Herby the researchers acknowledge the great help that was received from nurses and doctors work in the settings of data collection (selected primary health centers). Also the deepest gratitude is for the children and their mother whom without their cooperation and acceptance to be involved in the study we could not achieve the aim of the current study.

\section{References}

Abbaszadeh, R., Tabari, F., Taherian, K., \&Torab, S. (2017). Lavender aromatherapy in pain management: a review study, Pharmacophore, 8(3): 50-54. Retrieved from: http://www.pharmacophorejournal.com

Akgül, E.A., Karahan, Y., Başoğlu, F.S. et al. (2018). Effects of watching cartoons on pain scores in children undergoing venipuncture, Nursing Children and Young People; doi: 10.7748/ncyp.2018.e913

Algieri, F., Rodriguez-Nogales, A., Vezza, T., Garrido-Mesa, J., Garrido-Mesa, N., Utrilla, M.P., Gonzalez-Tejero, M.R., Casares-Porcel, M., Molero-Mesa, J., Del Mar Contreras, M., Segura-Carretero, A., Perez-Palacio, J., Diaz, C., Vergara, N., Vicente, F., Rodriguez-Cabezas, M.E. \& Galvez, J. (2016). Anti-inflammatory activity of hydroalcoholic extracts of Lavanduladentata L. and Lavandulastoechas L, J Ethnopharmacol; 190: 142- 
158. doi: 10.1016/j.jep.2016.05.063.

Ali, B., Al-Wabel, N.A., Shams, S., Ahamad, A., AlamKhan, S., \& Anwar, F. (2015). Essential oils used in aromatherapy: A systemic review, Asian Pacific Journal of Tropical Biomedicine; 5 (8): 601-611. Retrieved from: https://doi.org/10.1016/j.apjtb.2015.05.007

Arslan, I., Aydinoglu, S. \& Karan, N.B. (2020). Can lavender oil inhalation help to overcome dental anxiety and pain in children? A randomized clinical trial. Eur J Pediatr. Retrieved from: https://doi.org/10.1007/s00431020-03595-7.

Bikmoradi, A., Harorani, M., Roshanaei, G., Moradkhani, S., \& Falahinia, G.H. (2016). The effect of inhalation aromatherapy with damask rose (Rosa damascena) essence on the pain intensity after dressing in patients with burns: a clinical randomized trial, Iran. J. Nurs. Midwifery Res.; 21 (3): 247e254.doi: 10.4103/17359066.180380

Bikmoradi, A., Khaleghverdi, M., Seddighi, I., Moradkhani, S., Soltanian, A., \& Cheraghi, F. (2017). Effect of inhalation aromatherapy with lavender essence on pain associated with intravenous catheter insertion in preschool children: A quasi-experimental study. Complementary Therapies in Clinical Practice; 28: 85-91: www.elsevier.com/locate/ctcp

Bikmoradi, A., Zafari, A., Oshvandi, K., Mazdeh, M., \&Roshanaei, G. (2014). Effect of progressive muscle relaxation on severity of pain in patients with multiple sclerosis: a randomized controlled trial. Hayat; 20 (1): 26-37.

Chauhan, V. (2016). Formulation and evaluation of herbal pain relief oil. European Journal of Pharmaceutical and Medical Research; 3(4):515-520. www.ejpmr.com

Chawda, M., Malini, G., Saha, S., Chawda, S., Jha, C., Wanare, A., Pandey, R., \& Someshwar, H. (2019). Vaccination Related Pain: Randomized Controlled Trial, Comparison of Pain of Two Injection Techniques. American Journal of Pediatrics; 5 (3): 133-141

Ciftci, E.K, Ozdemir, F.K., \& Aydın, D. (2016). Effect of flick application on pain level and duration of crying during infant vaccination. Italian Journal of Pediatrics; 42(8) .doi: 10.1186/s13052-016-0218-y

Cohen, M., Quintner, J., \& Van Rysewyk, S. (2018). The International Association for the Study of Pain definition of pain: As valid in 2018 as in 1979, but in need of regularly updated footnotes. Reconsidering the IASP definition of pain. PAIN Reports; e634. DOI: 10.1097/PR9.0000000000000643

Crellin, D.J., Babl, F.E., Santamaria, N., \& Harrison, D. (2018). A Systematic Review of the Psychometric Properties of the Modified Behavioral Pain Scale (MBPS). J Pediatr Nurs. ;40: 14-26. Retrieved from: https://doi: 10.1016/j.pedn.2018.02.005. Epub 2018 Feb 16

Crellin, D.L., Harrison, D., Hutchinson, A., Schuster, T., Santamaria, N.\& Babl, F.E. (2017). Procedural Pain Scale Evaluation (PROPoSE) study: protocol for an evaluation of the psychometric properties of behavioural pain scales for the assessment of procedural pain in infants and children aged 6-42 months. BMJ; 7:e016225. doi:10.1136/bmjopen-2017-016225

DaSilveira e Sá, R.C., Lima, T.C., da Nóbrega, F.R., de Brito, A.E., and de Sousa, D.P. (2017). Analgesic-Like Activity of Essential Oil Constituents: An Update. International Journal of Molecular Sciences Int J Mol Sci.; 18 (12): 2392. doi: 10.3390/ijms 18122392

Elbay, U.S., Elbay, M., Kaya, E., \& Cilasun, U. (2016). Intra-ligamentary and supra-periosteal anesthesia efficacy using a computer controlled delivery system in mandibular molars. J Clin Pediatr Dent; 40:193-199.

Gad R., Dowling, D., Abusaad, F., Bassiouny, M ., \& Abd El Aziz, M. (2019). Oral Sucrose Versus Breastfeeding in Managing Infants' Immunization-Related Pain: A Randomized Controlled Trial. The American Journal of Maternal/Child Nursing; 44 (2): 108-114.

Giordano, C.N., Nelson, j., Kohen, L.L., Nijhawan, R., \&. Srivastava, D. (2015). Local anesthesia: Evidence, Strategies, and Safety. Curr. Derm. Rep. ; 4 (3) :97-104

Halpert, C., Meier, S., \& Naus, M. (2015). Reducing immunization injection pain in infants. BCMJ; 57 (5): 189.

Karaman, T., Karaman, S., Dogru, S., Tapar, H., Sahin, A., Suren, M., Arici, S., \&Kaya, Z. (2016). Evaluating the efficacy of lavender aromatherapy on peripheral venous cannulation pain and anxiety: A prospective, randomized study. Complementary Therapies in Clinical Practice; 23: 64-68. Retrieved from: https://doi.org/10.1016/j.ctcp.2016.03.008

Karan, N.B. (2019). Influence of lavender oil inhalation on vital signs and anxiety: a randomized clinical trial. Physiol Behav ; 211:112676.

Kaviani, M., Maghbool, S., Azima, S., \& Tabaei, M.H. (2014). The effect of aromatherapy with salvia officinalis on the severity of labor pain in nulliparous women. Iran J Nurs Midwifery Res. ; 19(6):666-72.

Kenji, T., et al. (2019). Demographic and geographical characteristics of pediatric patients presenting to a convenient clinic at a large railway station in a metropolitan area of Tokyo. Medicine; 98 (33): e16818

Khalil, N.S., Ismaeel, M.S., Hassan, S.A., \& Heshamshawky, H. (2018). Effects of lavender oil inhalation on sternotomy related pain intensity in open heart surgery patients in Egypt. Clin. Pract. ;16(1):1005-1010, ISSN 2044-9038 
Lakhan, S.E. (2016).The Effectiveness of Aromatherapy in Reducing Pain: A Systematic Review and MetaAnalysis. Retrieved from: https://doi.org/10.1155/2016/815869

Lesage-Meessen, L., Bou, M., Sigoillot, J.C., Faulds, C.B., \& Lomascolo, A. (2015). Essential oils and distilled straws of lavender and lavandin: a review of current use and potential application in white biotechnology. Applied Microbiology and Biotechnology; 99 (8): 3375-85. doi: 10.1007 /s0 0253-015-6511.

MacDougall, M., Cunningham, S., Whitney, L., and Sawhney, M. (2019). Improving pediatric experience of pain during vaccinations: a quality improvement project. International Journal of Health Care Quality Assurance; 2019; 5(3): 116-124

MacLennan, C.A., \&Saul, A. (2014). Vaccines against poverty. Proceedings of the National Academy of Sciences; 111 (34): 12307-12. doi: 10.1073/pnas.1400473111.

Maedeh, S., Ronakb, S., Bijanc, N., Asrina, K., Karimd, N., Shahgheibie, S., \& Faribab, R. (2019).Comparison of the effect of entonox gas and aromatherapy with lavender on the severity of labor pain. Healthy Aging Research; 8:1.doi:10.35248/har.2019.8.1

Meghani, N., Tracy M.F., Hadidi, N.N., \& Lindquist, R. (2017). Part II: The effects of aromatherapy and guided imagery for the symptom management of anxiety, pain, and insomnia in critically ill patients: an integrative review of current literature. Dimens Crit Care Nurs; 36: 334-348. doi: 10.1097/DCC.0000000000000272.

Mohamed, H. (2020). Effect of cellphone interactive games on venipuncture pain among Ill hospitalized Egyptian toddlers and preschoolers. International Journal of Research in Paediatric Nursing; 2(1): 36-42.

Najafi, B., Fariba, F., Daem, R., Ghaderi, L., \& Seidi, J. (2016). The effect of Lavender Essence on pain severity after cesarean section under spinal anesthesia. Journal of Chemical and Pharmaceutical Sciences (JCHPS); 7: www.jchps.com

Polit, D., \& Beck, C. (2017). Essentials of nursing research: Appraising evidence for nursing practice. 7th. ed., Lippincott and Williams, London.

Popovic, Z., Matic, R., Bojovic, S., Stefanovic, S., \& Vidakovic, V. (2016). Ethnobotany and herbal medicine in modern complementary and alternative medicine: an overview of publications in the field of I \& $\mathrm{C}$ medicine 2001-2013. J Ethnopharmacol.; 181;182-192. doi: 10.1016/j.jep.2016.01.034. Epub 2016 Jan 22.

Razaghi, N., Hoseini, A.S., Aemmi, S.Z., Mohebbi, T., \& Boskabadi, H. (2015). The Effect of Lavender Scent on Pain of Blood Sampling in Term Neonates. Int J Pediatr; 3, (16): 2-2. Retrieved from: http:// ijp.mums.ac.ir

Seifi, Z., Beikmoradi, A., Oshvandi, K., Poorolajal, J., Araghchian, M., \& Safiaryan, R. (2014). The effect of lavender essential oil on anxiety level in patients undergoing coronary artery bypass graft surgery: a doubleblinded randomized clinical trial, Iran. J. Nurs. Midwifery Res.; 19 (6): 574-580.

Stevens, K., and Marvicsin, D. (2016). Evidence-Based Recommendations For Reducing Pediatric Distress During Vaccination. Journal of Pediatric Nursing; 42: 6: 267-299

Taddio, A., Nulman, I., Koren, B. S., Stevens, B., \& Koren, G. (1995). A revised measure of acute pain in infants. Journal of pain and symptom management; 10(6): 456-463.

Ueki, S., Matsunaka, E., Swa, T., Ohashi K., \& Makimoto, K. (2015). Effectiveness of inhalation of aromatherapy in reducing anxiety in patients before colonoscopy, a systematic review protocol, JBI Database System Rev Implement Rep. ; 13(9):40-50. doi: 10.11124/jbisrir-2015-2234.

Vaziri, F., Khosropoor, M., Hidari, M., Pourahmad, S., Behbahani, B.M., \& Saki, F. (2019). The Effect of aromatherapy by lavender oil on infant vaccination pain: a double blind randomized controlled trial. Journal of Caring Sciences; 8 (1): 17-21. doi:10.15171/jcs.2019.003. Retrieved from: http:// journals.tbzmed.ac.ir/ JCS

Victoria, N. C., \& Murphy, A. Z. (2016). Exposure to Early Life Pain: Long Term Consequences and Contributing Mechanisms. Current opinion in behavioral sciences; 7: 61-68. Retrieved from: https:// doi.org/ 10. 1016/ j.co beha.2015.11.015

Ziyaeifard, M., Zahedmehr, A., Ferasatkis, R., Faritous, Z., Alavi, M., Reza Alebouyeh, M., Dehdashtian, E., Ziyaeifard, P., \& Yousefi, Z. (2017). Effects of Lavender Oil Inhalation on Anxiety and Pain in Patients Undergoing Coronary. Iranian Heart Journal; 18(1):44-50. 